\title{
JANE TUTIKIAN ENTREVISTA HELDER MACEDO, UM DOS GRANDES ESCRITORES PORTUGUESES DA ATUALIDADE
}

1

JT: O panorama geral da literatura portuguesa nos mostra que a grande marca desta literatura, nas últimas décadas tem sido o diálogo com a História. De um lado, há certa quantidade de escritores instalados dentro da relação tradicional e outros, na relação de leitura crítica, de subversão da História. E não é difícil perceber que esse diálogo termina colocando a literatura portuguesa numa posição privilegiada em relação à literatura européia. Em que medida isso se relaciona a revoluções praticamente simultâneas, a dos Cravos e a da Globalização?

HM: Os portugueses sempre tiveram a obsessão da História ou, talvez mais propriamente, da História que imaginam ser a sua. Daí o movimento pendular entre uma ideia excessiva de grandeza e um sentimento excessivo de decadência. O império foi uma impossibilidade realizada contra as expectativas que teriam sido normais num país pobre e pequeno. Mas não foi um factor de enriquecimento da maioria da população, ao contrário do que aconteceu noutras nações imperiais igualmente pequenas, como por exemplo a Holanda, onde levou à criação de uma poderosa classe média. A aventura imperial portuguesa levou à criação de elites parasíticas e à marginalização da maioria potencialmente produtiva. Não é por acaso que, ainda em meados do Século XX, com uma colónia tão rica como Angola, Portugal permanecesse um dos países mais pobres da Europa Ocidental. E, antes disso, tinha havido o Brasil. Sá de Miranda, no Século XVI, e Antero de Quental, no Século XIX, tiveram bastante razão quando consideraram o império uma causa da decadência do país. O 25 de Abril de 1974, a chamada Revolução dos Cravos, não permitiu apenas que as colónias se tornassem independentes de Portugal, permitiu que Portugal se tornasse independente das colónias, levou à descolonização de Portugal, permitiu que Portugal se tornasse num país normal, um país mais parecido com os outros. O que também teve a ver com a entrada na Comunidade Europeia e, é claro, como bem sugeres, com o fenómeno mais amplo da Globalização. A qual, de algum modo, pode ser entendida como uma nova forma de imperialismo mais ou menos desnacionalizado, mas isso é outro assunto que nos levaria para futuros ainda imprevisíveis. Voltando à tua pergunta: sim, vários escritores portugueses actuais dialogam com a História. E, dada a complexidade da História de Portugal (o tal movimento pendular entre percepção de grandeza e percepção de decadência), talvez que os escritores portugueses estejam confrontando de um modo particularmente evidente, porque concentrado num pequeno país com uma longa História, uma problemática comum a outros países europeus. A globalização, de uma perspectiva cultural, é um fenómeno que está acontecendo em língua inglesa, é um produto da pax americana. Todas as outras culturas europeias também estão mais ou menos marginalizadas, tornaram-se periféricas até em relação a si próprias. Alguns escritores portugueses têm manifestado a sua relação com a História continuando a tendência autoflageladora cristalizada na visão pesadélica da História de Portugal representada na obra oitocentista de Oliveira Martins. É o caso, por exemplo, de um escritor brilhante como António Lobo Antunes. Outros, mais saudavelmente, têm vindo a buscar novas vias de percepção. Seja como for é interessante notar que muitos escritores portugueses contemporâneos só descobriram a África depois da independência das colónias e, muitos 
deles, com base nos traumas das guerras coloniais em que participaram. E alguns agora também começam a redescobrir o Brasil, o que só lhes faz bem. Mas outros têm preferido descobrir Portugal. Foi o caso de José Cardoso Pires, que considero o fundador da nova ficção portuguesa, e é o caso de José Saramago. Repara: o Saramago nunca escreveu sobre África ou sobre as guerras coloniais. Mesmo quando escreve romances históricos objectivamente estruturados até ao mais pequeno pormenor, é um escritor de fábulas. Muitos dos seus romances poderiam começar não com o "era uma vez" das narrativas tradicionais mas com um "e se" de narrativas sobre possíveis mundos alternativos. É um escritor que fala para o futuro. Soube situar-se no centro da consciência europeia de si própria. Nem que fosse só por isso, mereceu o Nobel.

\section{2}

JT: Quem persegue quem? O autor persegue o tema ou vice-versa? Pergunto isso porque, desde Partes de África, de 1991, e esse livro representou uma ruptura na Literatura Portuguesa, pela estrutura híbrida e fragmentada e por um narrador não digno de confiança que se confunde com o próprio autor, conduzindo um discurso ponte entre a tradição literária e a inovação, a identidade tem sido um tema recorrente. Isso tem a ver com a identidade do autor português nascido na África, ou com a grande busca do nosso tempo, esta fronteira em que se perdem os chamados valores absolutos éticos, estéticos, filosóficos, com que até então se viveu, para a construção de outros ainda mal definidos?

HM: As duas coisas, alternadamente. Talvez comece por ser o tema que persegue o autor que depois persegue o tema que depois persegue o autor e assim por diante. Quando comecei a escrever Partes de África pensei que ia escrever poesia. Daí talvez a sua estrutura estrófica, resultando numa obra simultaneamente fragmentada em partes, ou "estrofes", e articulada num conjunto multifacetado. O arranjo formal de um livro, a sua estrutura, faz parte da sua significação, é tanto um significante quanto é o estilo ou, num romance, as situações e as personagens. Já foi dito, e creio que com alguma razão, que esse livro foi o primeiro romance "pós-colonialista" escrito em Portugal. Talvez, por isso, cedo demais para os leitores e, sobretudo, os críticos portugueses, que não souberam muito bem o que fazer dele. Os portugueses viviam ainda em plena ressaca colonialista, num período de transição entre o que tinham sido e o que desejariam poder ser. Precisavam de simplificar a História, de considerar que, de um lado, havia os bons e, do outro, havia os maus. Entender o bom no mau e o mau no bom, como procurei fazer, não dava muito jeito para a arrumação da nova casa portuguesa. A qual, afinal, não era assim tão nova, estava era sendo pintada de novas cores. Mas, por isso mesmo, também não foi por acaso que o livro tenha sido logo melhor entendido, e fosse particularmente bem recebido, no Brasil, uma nova nação já verdadeiramente póscolonial. Que alguém como eu, clara e publicamente identificado com a revolução e com o anticolonialismo, tivesse procurado entender por dentro o colonialismo não poderia ter deixado de causar alguma confusão em almas confusas. E sim, tens razão quando sugeres que a minha perspectiva pode ter alguma coisa a ver com o facto de eu ter nascido e passado a minha infância em África. Também certamente com o facto de ser filho e neto de governantes coloniais e depois, desde a minha adolescência em Portugal, de ter percebido que a miséria e a exploração da miséria não tinham cor, ou seja, que o colonialismo português não começava nas colónias mas em Portugal, na Europa, exercido por portugueses sobre outros portugueses. A posição da minha família de colonialistas bem intencionados e a minha posição de rebeldia que me 
colocou simultaneamente dentro e fora do colonialismo permitiram-me definir as zonas intervalares onde os valores absolutos se relativizam porque é onde as identidades circunstanciais se definem. Nunca ninguém é como foi nem como vai ser, só pode ser como está sendo, mesmo quando não dá por isso. O narrador de Partes de África, o meu eu autoral parcialmente autobiográfico, só não é digno de confiança para poder ser digno de confiança quando mostra que só pode falar a partir das suas percepções, ideias e experiências. Como, afinal, todos nós sempre fazemos, mesmo quando aparentamos ser objectivos. Não há outro modo de ser verdadeiro além de mostrar a subjectividade inerente a toda e qualquer representação da veracidade. Por isso Partes de África não é autobiografia e, menos ainda, História, embora tenha elementos de ambas. É uma obra de ficção, é um romance. Se isto, em termos literários, resultou, como dizes, num "discurso ponte entre a tradição literária e a inovação”, o mérito é da própria realidade a que procurei dar uma forma estética tão adequada quanto me foi possível.

\section{3}

JT: A inquietação estética se mantém em Pedro e Paula (1998) e nos seguintes, e se mantém o narrador - Helder Macedo -, analisando a criação do texto, mas, o que aqui se coloca é uma leitura outra da história portuguesa quando, em novos tempos, tempos se confrontam. Explico: o antes e o depois da Revolução dos Cravos. Pedro, o conservador, Paula, a mudança. Como se dá, na identidade portuguesa, a convivência desses dois? O fechado, preso às tradições, e o novo, aberto às inovações?

HM: Ah, essa Paula! Há quem diga que ela é a minha personagem mais autobiográfica. Não é inteiramente verdade, eu sou homem e ela é mulher, mas certamente é uma mulher com quem eu me teria podido identificar. E que por isso, no livro, mostro que teria podido desejar, se ela existisse. Desejando quem não sou nem poderia ser. O oposto de narcisismo, portanto. Mas tudo isso são ficções, é parte de uma retórica da verosimilhança, de modo a tornar mais aparentemente factual uma personagem fictícia e tornar mais evidentemente fictícia a personagem factual do autor. Explicando melhor: se, num romance, uma personagem que corresponde a alguém que factualmente existe contracena com uma personagem que factualmente não existe, a personagem que factualmente existe torna-se fictícia e a personagem fictícia adquire maior veracidade. Foi essa a estratégia literária que iniciei em Partes de África e que desenvolvi em Pedro e Paula. Mas, enquanto que naquele livro me usei como veículo funcional, neste, para dar significação ao período histórico de transição entre o antes e o depois da Revolução dos Cravos, achei que a personagem dinâmica que poderia representar a metamorfose de um passado tradicionalista num futuro libertário, tinha de ser uma mulher. A grande revolução do nosso tempo foi a libertação da mulher. Ainda não se completou e está longe de ter sido alcançada entre as classes sociais menos privilegiadas, mas está acontecendo. Está acontecendo em todo o mundo ocidental e, não menos, em Portugal, no Portugal que pôde começar a haver depois da Revolução dos Cravos. Outros aspectos da revolução portuguesa têm sido mais ou menos neutralizados, esse já não poderá ser. Basta observar a predominância de mulheres na nossa literatura actual, ler uma romancista como a Lídia Jorge, ler a poesia da Maria Teresa Horta. E o facto é que a libertação da mulher não tem só a ver com mulheres, tem a ver com todos nós, mulheres e homens. A libertação da mulher é imprescindível para a libertação do homem e vice-versa. Como também teria podido dizer o bom do Marx se aquela sua análise juvenil sobre a equivalente alienação reciprocamente causada pelos opressores nos oprimidos e 
pelos oprimidos nos opressores não tivesse incidido sobre a luta de classes mas sobre a complementaridade dos sexos. Nesse contexto, ele disse que o "desassossego" mutuamente libertador só poderia resultar da revolta dos oprimidos contra a sua própria condição de alienados, já que os alienados opressores estão perfeitamente satisfeitos na sua própria alienação, como é o caso de Paulo nesse meu romance. Paula, pelo contrário, personifica o desassossego potencialmente libertador de si própria e dos outros. Como bem sabes, Pedro e Paula até pelo título remete a Esaú e Jacó, é um romace de referência machadiana. A fundamental e deliberada diferença é que, no romance de Machado, os gémeos masculinos Pedro e Paulo são idênticos na sua oposição em nome de valores só aparentemente antagónicos porque finalmente também idênticos, e que uma personagem feminina, Flora, que teria podido amar qualquer dos dois, naturalmente não consegue escolher entre eles e morre de indecisão. Enquanto que a minha Paula é uma mulher que se diferencia do seu masculino irmão gémeo, Paulo. Aliás, em termos machadianos, Paula é mais Capitu do que Flora. Mas, como os tempos felizmente mudaram, é uma Capitu que já não precisa de ser sacrificada aos valores patriarcais e masculinos, como também, no meu livro, a mãe de Paula havia sido. É esse o antes e o depois que o meu livro procura representar e que, sendo afinal mais amplo do que o antes e o depois da Revolução dos Cravos, a inclui como um facto significativo de um processo nela simbolizado.

\section{4}

JT: Vícios e virtudes, publicado em 2002, é a explosão irônica da repensagem sobre o processo de criação literária , sobre a academia, nossas crenças e nosso tempo. Começa por "brincar" com aquele que é o ícone da identidade portuguesa: D. Sebastião. Francisco de Sá é uma caricatura do escritor contemporâneo e , através dele, H.M. o outro escritor, conhece Joana, cuja biografia tem fortes ligações com a da Áustria, a mãe de D. Sebastião. É o mote para o romance dos dois escritores, o de H. M. o que se cria no próprio ato da leitura, como no próprio ato da escritura se cria a identidade de Joana que se nega a receber a identidade histórica que lhe é imposta e, estabelecendo um jogo de espelhamentos entre si mesma e as diferentes "versões", históricas ou ficcionais, que lhe são conferidas, torna-se autora de própria, restando fragmentos de uma identidade cuja única existência é a ficcional. Essa é mesmo uma metáfora do sebastianismo e da identidade portuguesa? Quando Francisco de Sá evoca "O Encoberto” como símbolo da identidade nacional, o narrador responde: "Uma ova a identidade nacional, não há tal coisa. Há pessoas e circunstâncias”. E o comprova, demonstrando, através deste mosaico que é Joana, que toda identidade é uma construção ficcional, ou seja: a união de fragmentos da memória, da imaginação e da História. É isso mesmo?

HM: Sim, é isso mesmo: não há tal coisa como identidade nacional, há pessoas e circunstâncias. Mudadas as circunstâncias, as pessoas também mudam. O que também significa que não há $\mathrm{D}$. Sebastião mesmo quando continua a haver sebastianismo e outras tontices equivalentes. Mas há, é claro, identidades culturais, há uma História comum, há uma sociedade partilhada, há uma literatura em que tudo isso se manifesta. A Joana de Vícios e Virtudes, metaforicamente correspondente à princesa Joana que foi mãe de D. Sebastião, é uma personagem que se recusa a ser manipulada pela escrita que lhe impusesse uma identidade que não derivasse de si própria. Neste romance levei ao extremo a ficcionalização autoral autobiográfica que iniciara em Partes de África e retomara em Pedro e Paula. Dos dois autores que teriam escrito sobre as falsificações históricas do que 
essa Joana fosse em Vícios e Virtudes, o mais perverso não é o mais tonto dos dois, o Francisco de Sá que papagueia tretas sobre a identidade nacional, é o que coincide com o eu autoral, é aquele cujas circunstâncias coincidem com as de um Helder Macedo factual e aparentemente autobiográfico. Aquele que, tal como eu próprio, ridiculariza as tontices sobre a identidade nacional e que satiriza, na personagem do outro escritor, o Francisco de Sá, as tontices de uma literatura escrita num português que parece ser traduzido de uma lingua estrangeira que não há, como tanta que actualmente se pratica entre nós. A perversidade desse Helder Macedo enquanto personagem de mim próprio vem de eu ter usado a minha veracidade factual para a falsificar numa aparência de veracidade. Por isso esse Helder Macedo que biograficamente coincide com quem sou foi justamente punido pela Joana que teria sido sua personagem, quando ela lhe escreve aquela terrível carta em que o desconstroi para depois se poder desconstruir a si própria, desaparecendo do livro que ele estava escrevendo sobre ela. Excepto, evidentemente, que quem escreveu essa Joana, e escreveu a carta que ela escreve a esse Helder Macedo, fui eu, o autor do livro, o Helder Macedo que não entra no livro e que portanto nunca conheceu essa Joana. Fui eu a tentar entender e a desejar que os meus potenciais leitores procurem entender as falsificações inerentes a toda e qualquer veracidade literária que pretenda substituir-se à sempre incapturável veracidade das pessoas que há nas suas sempre mutáveis circunstâncias. Como diz Joana que não é a mãe de D. Sebastião, não se pode beber água da palavra água.

\section{5}

JT: E a Júlia de Sousa, duplo de Marta, em Sem Nome (2005)? Pode-se afirmar que o reconhecimento que Júlia faz de si mesma passa pelo conhecimento da história recente de Portugal, e pela mesma compreensão da construção/desconstrução das identidades, respaldada pela ambivalência real/ imaginário?

HM: Júlia de Sousa, essa jovem aspirante a jornalista mas afinal ficcionista, constroi uma falsa realidade que se transforma e substitui uma realidade factual que nunca se chega a saber qual possa ter sido. A sua mentira tornou-se numa falsa verdade que, por poder ser assumida como verdadeira, simultaneamente se torna libertadora dos fantasamas do passado e torna possível um futuro libertado desses fantasmas. Mas isso é a natureza da História, não é? O que geralmente se entende como História não é a História como aconteceu, é a escrita da História, é uma ficcionalização do passado da perspectiva do presente. Todo o passado é sempre contado da perspectiva do presente. Só os sobreviventes têm História, mesmo quando a História que contam possa parecer ser a dos outros, a História dos que não sobreviveram. O que também procurei mostrar neste livro, no entanto, foi que Júlia, através da sua mentira, conseguiu encontrar uma veracidade própria que se tornou na sua própria veracidade. A Júlia cresceu ao longo do livro, deixou de ser "sem nome”, deixou de ser alguém cuja identidade teria consistido apenas em parecer ser uma duplicação de quem não podia ser, aquiriu uma identidade própria. Procurei escrever um romance de aprendizagem contado no seu reverso. $\mathrm{O}$ paradoxo inerente à personagem de Júlia foi que, através de uma mentira assumida como tal - mas que é uma mentira do que teria podido acontecer sem que se possa saber se aconteceu ou não - ela alcançou uma integridade que de outro modo nunca teria alcançado. Chegou a uma plausível veracidade sobre si própria, ou seja, à sua identidade pessoal e socialmente actuante pela via de uma mentira que sabe ser mentira mas que poderia ter sido verdade. Ao saber que a mentira é mentira, no entanto, mesmo se uma mentira útil e funcionalmente positiva, está também 
definindo áreas alternativas de veracidades potenciais que permanecem latentes e se mantêm inalcançáveis. Por tudo isso julgo que Sem Nome é uma alegoria política porque é também uma representação da História não só como reconstrução do passado mas também, enquanto jornalismo, como tentativa de agir sobre um presente que está decorrendo. E isto, afinal, é igualmente o que faz a literatura. Mas, se o livro é uma alegoria, não creio que ela incida apenas sobre o Portugal contemporâneo à sua escrita e que, jornalisticamente, utiliza como um entre vários outros elementos da sua construção literária. O facto, no entanto, é que os sempre ambíguos processos literários da veracidade histórica são iguais em toda a parte.

6.

JT: Escrever Natália (2008) deve ter sido um grande exercício de criação - pela forma diarística, de um lado, pelo jogo entre o diário e o livro do escritor, de outro, e, de outro, ainda, pela percepção de vida e imaginação do ponto de vista de uma jovem mulher, órfã de pai e mãe, assassinados na Argélia pouco antes de 1974 pela polícia secreta portuguesa e criada pelo avô, - norteado pela pergunta «Quem sou eu?». Mas, aqui, a presentificação do passado não devolve ao presente a significação... Ou a significação do presente se assenta nas relações interpessoais, como a relação com Fátima, por exemplo?

HM: Bom, sim, não foi fácil escrever Natália. Não sou mulher, estou longe de ser jovem (a Natália teria 27 anos quando o livro começa) e ainda por cima nunca escrevi um diário. Tive de trabalhar com muita atenção para escrever num estilo totalmente diferente do meu habitual, procurando dar através dele não só uma percepção feminina das coisas - a percepção de Natália que, a mais das vezes, não coincide com a minha - mas também escrevendo como se apressadamente, com repetições e até erros que eu não cometeria. São coisas que geralmente se conseguem com alguma facilidade nos diálogos que, simultaneamente, servem para caracterizar as personagens através do modo como falam e para fazer avançar a narrativa global do livro em que se integram. Mas aqui a fala da personagem tinha de ser o livro todo. E, através dela, eu tinha de fazer significar coisas que ela não teria sabido como dizer, apontar para uma significação mais ampla e, espero, mais profunda do que ela teria sido capaz de exprimir. Creio que o livro, se funciona, funciona nesse zona intervalar entre o que é dito pela personagem e o que não é dito pelo autor. Natália interpreta a realidade de acordo com a sua percepção, modifica a realidade, por exemplo reinterpretando à sua maneira o que Fátima lhe diz. A Fátima que é, ou se torna, numa espécie de projecção alternativa de Natália, a mulher que ela ama, ou que julga amar, porque não consegue amar-se a si própria. A relação física de Natália com Fátima é menos um encontro sexual entre as duas mulheres, ou seja, a relação lésbica que também é, quanto uma reconstrução mitificada de carências infantis. A sexualidade que une as duas é sobretudo um veículo, a forma possível de uma recuperação impossível de um passado que talvez nunca tenha sido como ambas imaginaram que fosse através da personagem mitificada do avô de Natália e mentor de Fátima, uma personagem tutelar cuja memória acaba por ser desfigurada através da neutralização de Fátima por Natália e de Natália por Fátima. Mas, com todos os defeitos e limitações que o personagem mitificado do avô possa ter tido, por falso que tenha sido o passado que ele representa, a essência do processo mítico que ele personificara, e que se sobrepõe ao texto narrativo do romance, permanece e acaba por triunfar para além das circunstâncias transitórias das duas jovens que, por causa dele, se amaram e se perderam. Curiosamente, nenhuma das mulheres que escreveram em 
Portugal sobre este livro, e foram várias, teve qualquer problema em entender a relação erótica entre essas duas mulheres. Até entenderam que só na aparência é uma relação erótica. Mas houve um homem, um daqueles críticos literários que passam a vida a reconhecer o que presumem conhecer, que teve dificuldade em entender o jogo de espelhos inerente a essa relação e, consequentemente, também não entendeu o carácter alucinatório do livro. Se calhar julgava que iria ficar sexualmente titilado e afinal, coitado, não ficou. Mas os homens são em geral sexualmente mais primitivos do que as mulheres, não achas? 